\title{
High prevalence of asthma in cross country skiers
}

\author{
Kjell Larsson, Peter Ohlsén, Lars Larsson, Per Malmberg, Per-Olov Rydström, Hans Ulriksen
}

\section{Abstract}

Objectives-To study the prevalence of asthma (asthma symptoms and bronchial hyperresponsiveness) in Swedish cross country skiers compared with non-skiers and monitor changes in symptoms and bronchial hyperresponsiveness during the year.

Design-Cross sectional study during the winter ski season and in the summer.

Setting-Six ski clubs for élite skiers (total 47) in two different areas of Sweden.

Subjects -42 élite cross country skiers and 29 nonskiing referents.

Main outcome measures-Bronchial responsiveness, asthma symptoms, and lung function.

Results-Bronchial responsiveness was significantly greater and asthma symptoms more prevalent in the skiers than in the referents. There was no difference in bronchial responsiveness within either group between winter and summer. 15 of the 42 skiers used antiasthmatic drugs regularly and $23 \mathrm{had}$ a combination of asthma symptoms and hyperresponsive airways or physician diagnosed asthma, or both. Altogether 33 skiers had symptoms of asthma or bronchial hyperresponsiveness. One of the referents had symptoms of asthma and bronchial hyperresponsiveness, and none used antiasthmatic drugs regularly.

Conclusions-Asthma, asthma-like symptoms, and bronchial hyperresponsiveness are much more common in cross country skiers than in the general population and non-skiers. Strenuous exercise at low temperatures entailing breathing large volumes of cold air is the most probable explanation of persistent asthma in skiers.

\section{Introduction}

Asthma is not an obstacle to athletic activities, and there are very successful competitive athletes who have asthma. ${ }^{1}$ Swedish doctors who are consultants to the ski clubs have observed that airways symptoms and the use of antiasthmatic drugs, mainly $\beta_{2}$ stimulants, are more common among cross country skiers than in nonskiers. This has recently been confirmed by a postal inquiry. ${ }^{2}$ Cross country skiing differs from most other sports, in that the athletic effort is conducted at low temperature. Training and competitions are often performed in temperatures below $-15^{\circ} \mathrm{C}$, implying ventilation with large amounts of cold air for several hours a week, for several months of the year. Inhaling cold air is a trigger for bronchoconstriction in asthmatic subjects. ${ }^{34}$ To our knowledge, however, there has been no report suggesting that breathing large amounts of cold air for long periods causes asthma in healthy subjects. To elucidate matters we undertook a study of asthma-like symptoms, lung function, and bronchial responsiveness in élite cross country skiers and referents. To see whether possible differences between the skiers and referents might be observed only during the ski season we conducted identical trials in the winter and in the summer.

registrar, department of internal medicine

Correspondence to:

Dr Kjell Larsson.
Subjects and methods

All 47 élite skiers from six Swedish cross country ski clubs were invited to participate. Clubs were selected on two grounds: most of the members were élite skiers, and the clubs were located near the two centres (Stockholm and Ostersund) where the study was performed. Five of the 47 skiers did not attend, leaving 42 who participated ( 36 men, six women; mean age 24 (range 16-50)), most of who were national élite skiers. They had been active competitors for 13 (range 6-23) years, and the estimated mean training time in the year before the study was 406 (100-680) hours. Referents were 29 healthy hospital or laboratory workers and students (24 men, five women; mean age 28 (20-45) years). Referents were invited to participate if they were aged 20-50 and were never smokers. None were skiers.

Owing to the locations of the clubs participants were investigated in different laboratories. Fourteen skiers and 12 referents were investigated in Stockholm; 28 skiers and 17 referents were investigated in Ostersund in central Sweden. All subjects were investigated twice: in the winter (March and April) and in the summer (August and September). At the first visit subjects were tested by skin prick with a standard panel of 10 allergens (Phazet; Pharmacia, Uppsala, Sweden). At both visits subjects were interviewed and underwent spirometry and a bronchial provocation test with methacholine.

Forced expiratory volume in one second and vital capacity were measured with a low resistance rolling seal spirometer (OHIO 840; Ohio Medical Products, Madison, Wisconsin) in Stockholm ${ }^{5}$ and a Morgan Auto-Link ( $\mathrm{P} \times$ Morgan Ltd, Chatham, Kent) in Ostersund. Forced expiratory volume in one second was taken as the highest of three readings. In addition, slow vital capacity measurements were done and the final value stated as the highest recorded in three forced and three slow expirations. Residual volume was measured at a respiratory rate of $25 / \mathrm{min}$ in a volume constant body plethysmograph (Eric Jaeger, GmbH, Würzburg, Germany) in Stockholm and in a modified pressure compensated volume displacement body box (Ohio Medical Products) in Ostersund. Reference values were obtained from Hendenström et al. ${ }^{67}$

In Stockholm the methacholine challenge tests were performed with a jet nebuliser (model MA2, Astra Meditec, Gothenburg, Sweden) with an output of 0.38 $( \pm 0.013) \mathrm{ml} / \mathrm{min}$. The method has been described. ${ }^{8} \mathrm{In}$ Ostersund the tests were performed with an Aiolos Inhaler System (Aiolos Medicinsk Teknik AB, Karlstad, Sweden) with an output of $0.7 \mathrm{ml} / \mathrm{min}$. Tests began with inhalation of the diluent followed by inhalation of increasing concentrations of methacholine, starting at $2.6 \mathrm{mmol} / \mathrm{l}(0.5 \mathrm{~g} / \mathrm{l})$; each increment represented a doubling of the concentration. Inhalations were performed at a respiratory rate of $15 / \mathrm{min}$ during one (Stockholm) or two (Ostersund) minutes. Measurements of forced expiratory volume in one second were performed with a wedge spirometer (Vitalograph; Buckingham, England), beginning one minute after the inhalation. The interval between dose steps was six minutes. The result was expressed as the provocative concentration of methacholine required to produce a $20 \%$ fall in forced expiratory volume in one second $\left(\mathrm{PC}_{20}\right.$ methacholine). In addition, the slope of the change in forced expiratory volume in one second as a function of the cumulative methacholine dose was estimated by linear regression analysis. Broncho- 
dilators were withheld from 12 hours before the investigations. Inhaled steroids were continued.

At the standardised interview complaints of cough, abnormal shortness of breath, chest tightness, and wheezing induced by asthma trigger factors such as exercise or cold air or inhaled stimuli, or both, were noted. Bronchial hyperresponsiveness was defined as a $\mathrm{PC}_{20}$ methacholine below the 10 th centile of the values in referents. Asthma was defined as bronchial hyperresponsiveness plus two of the symptoms listed above.

Statistics-Results are presented as means and standard deviation (SD) or median values (25th-75th centiles). Statistical comparisons were by Student's $t$ test for unpaired and paired observations (lung function), the Mann-Whitney U test and Wilcoxon's signed rank sum test (bronchial responsiveness), and the $\chi^{2}$ test (symptoms). $p$ Values $<0.05$ were considered significant.

\section{Results}

Lung function data are given in table I. Vital capacity, total lung capacity, and forced expiratory volume in one second were significantly greater in the skiers than in the referents. By contrast, no significant difference was observed with regard to residual volume and forced expiratory volume in one second/vital capacity. In the skiers residual volume and vital capacity were significantly greater in the winter $(p<0.05)$, although the differences in group mean values were small $(0 \cdot 14$ and 0.051 respectively). No difference between winter and summer values with regard to any lung function parameter was observed in the referent group.

Data on bronchial responsiveness are given in table II. Skiers had an increased bronchial responsiveness as compared with the referents (provocative concentration and slope) both in winter and in summer $(p<0.01)$. There was no significant difference in bronchial responsiveness between winter and summer in either group.

The prevalence of atopy (one or more positive reactions in the skin prick test) was similar in the two groups (12 of the 42 skiers, and six of the 29 referents; NS). Cough, abnormal shortness of breath, chest tightness, and wheeze related to exercise, cold, or inhaled stimuli were significantly more common in the skiers (table III). There was no difference in the occurrence of symptoms between winter and summer.

Fifteen of the skiers used antiasthmatic drugs regularly. Thirteen inhaled $\beta_{2}$ agonists, 13 steroids, and two sodium cromoglycate. Asthma as defined by the study criteria was significantly more prevalent in

TABLE I-Lung function (measured in winter) in 42 cross country skiers and 29 referents. Values are means (SD)

\begin{tabular}{lccccc}
\hline & $\begin{array}{c}\text { Residual volume } \\
\text { (\% of predicted) }\end{array}$ & $\begin{array}{c}\text { Total lung } \\
\text { capacity } \\
\text { (\% of predicted) }\end{array}$ & $\begin{array}{c}\text { Vital capacity } \\
\text { (\% of predicted) }\end{array}$ & $\begin{array}{c}\text { Forced } \\
\text { volume in one } \\
\text { second } \\
\text { (\% of predicted) }\end{array}$ & $\begin{array}{c}\text { Forced expiratory } \\
\text { volume in one } \\
\text { second/vital } \\
\text { capacity (\%) }\end{array}$ \\
\hline $\begin{array}{l}\text { Skiers } \\
\text { Referents }\end{array}$ & $\begin{array}{c}108(24) \\
98(27)\end{array}$ & $107(9)$ & $110(10)$ & $112(11)$ & $83(6)$ \\
\hline $\begin{array}{l}\text { p Value for } \\
\text { difference }\end{array}$ & $>0.1$ & $<0.05$ & $<04(10)$ & $105(14)$ & $81(5)$ \\
\hline
\end{tabular}

TABLE III-Prevalence of symptoms in 42 skiers and 29 referents in winter

\begin{tabular}{lccc}
\hline & Skiers & Referents & $\begin{array}{c}\text { p Value } \\
\text { for difference }\end{array}$ \\
\hline Cough & 27 & 5 & $<0.01$ \\
Wheeze & 32 & 6 & $<0.01$ \\
Breathlessness & 17 & 4 & $<0.02$ \\
Chest tightmess & 24 & 0 & $<0.01$ \\
\hline
\end{tabular}

TABLE IV-Use of antiasthmatic drugs and prevalence of physician diagnosed asthma related to asthma diagnosis according to study criteria in 42 cross country skiers and 29 referents

\begin{tabular}{llrrrrr}
\hline & & \multicolumn{4}{c}{ Asthma } \\
\cline { 3 - 4 } & & \multicolumn{2}{c}{ Skiers } & & \multicolumn{2}{c}{ Referents } \\
\cline { 3 - 4 } \cline { 5 - 6 } & & Yes & No & & Yes & No \\
\hline Antiasthmatic drugs & Yes & 5 & 10 & & 0 & 0 \\
Physician diagnosed & No & 9 & 18 & & 1 & 28 \\
asthma & Yes & 4 & 9 & & 0 & 0 \\
No & 10 & 19 & & 0 & 29 \\
\hline
\end{tabular}

All 10 skiers who took antiasthmatic drugs and nine who had physician diagnosed asthma but did not fulfil our asthma criteria received inhaled steroids on regular basis.

the skiers $(14 / 42)$ than in the referents $1 / 29 ; p<0.01)$. Physician diagnosed asthma was reported by 13 of the 42 skiers and none of the referents. Nine of these 13 skiers had normal bronchial responsiveness and thus did not have asthma by our criteria. All nine skiers inhaled steroids regularly. Nine of the skiers who were classified as having asthma by our criteria were not taking antiasthmatic drugs regularly (table IV). None of the skiers had had asthma since childhood. Bronchial hyperresponsiveness without airways symptoms (two or more of cough, wheeze, breathlessness, and chest tightness) was observed in two skiers, and symptoms without bronchial hyperresponsiveness were observed in 17 skiers. Thus of the 42 skiers, $23 \mathrm{had}$ asthma according to our criteria or diagnosed by a physician and 33 had bronchial hyperresponsiveness or airways symptoms, or both, indicating asthma. Corresponding figures for the 29 referents were one and three respectively.

\section{Discussion}

This study shows that asthma, asthma-like symptoms, and bronchial hyperresponsiveness occur more frequently in cross country skiers than in healthy nonskiers. Moreover, in this series symptoms of asthma and bronchial hyperresponsiveness that were present in the winter - that is, at a time of strenuous training and competition in cold air-remained unchanged in the summer, when the skiers had not been exposed to cold air for several months.

Inhaling cold air induces bronchoconstriction and exacerbates the bronchoconstriction that occurs after exercise in patients with asthma. ${ }^{34}$ It has also been shown that inhaling cold air before a bronchial histamine provocation test transiently increases bronchial responsiveness in healthy ${ }^{9}$ and asthmatic subjects. ${ }^{10}$ In healthy subjects strenuous exercise in cold air induces a greater bronchoconstrictor response to histamine than exercise at room temperature. ${ }^{11}$ Thus data suggest that breathing cold air for a short period influences

TABLE II-Provocative concentrations of methacholine required to produce $20 \%$ fall in forced expiratory volume in on second (PC 20 methacholine) in skiers and referents in winter and summer, and slopes in the two groups. Values are medians (interquartile range)

\begin{tabular}{|c|c|c|c|c|}
\hline & \multicolumn{2}{|c|}{$\mathrm{PC}_{20}$ methacholine $(\mathrm{mmol} / \mathrm{l})$} & \multicolumn{2}{|c|}{ Slope $(\% / \mu \mathrm{mol})$} \\
\hline & Winter & Summer & Winter & Summer \\
\hline $\begin{array}{l}\text { Skiers } \\
\text { Referents }\end{array}$ & $\begin{array}{l}12 \cdot 7(5 \cdot 3-31 \cdot 2)[n=42] \\
33 \cdot 2(15 \cdot 1-327 \cdot 0)[n=29]\end{array}$ & $\begin{array}{l}14 \cdot 2(3 \cdot 8-41 \cdot 5)[n=37] \\
63 \cdot 4(13 \cdot 5-327 \cdot 0)[n=27]\end{array}$ & $\begin{array}{l}-1.96(-4.19 \text { to }-0.55)[n=42] \\
-0.37(-1.72 \text { to }-0.18)[n=29]\end{array}$ & $\begin{array}{l}-1.8(-4.74 \text { to }-0.47)[n=37] \\
-0.37(-1.72 \text { to }-0.18)[n=27]\end{array}$ \\
\hline $\mathrm{p}$ Value for difference & $<0.01$ & $<0.01$ & $<0.01$ & $<0.01$ \\
\hline
\end{tabular}


bronchial responsiveness in healthy and asthmatic subjects.

Swedish cross country skiers often train at temperatures below $-10^{\circ} \mathrm{C}$, and even $-15^{\circ} \mathrm{C}$, and competitions are permitted at $-17^{\circ} \mathrm{C}$. The most probable explanation for asthma and asthma-like symptoms among skiers is their intense exposure to cold air. Thus exposure to cold air may lead not only to a transient increase in bronchial responsiveness but to persistent asthma, as in this series symptoms and bronchial hyperresponsiveness were present to the same degree off season as in the winter.

We recorded asthma (as defined by our criteria and diagnosed by physicians) in over half of the skiers. Physician diagnosed asthma was recorded in 13 skiers $(31 \%)$. By comparison, the prevalance of physician diagnosed and self reported asthma in Sweden is $5-7 \% .^{1213}$ The prevalence of asthma based on reports of symptoms and bronchial hyperreactivity has been estimated as $6-8 \%$ in central Sweden. ${ }^{12}$ From these figures we should have expected to find three cases of physician diagnosed asthma among our 42 skiers. Our results therefore indicate a much higher prevalence of asthma in cross country skiers than in the general population.

We do not think that there was a selection bias in our series-that is, that asthmatic subjects were more inclined to take up skiing than other people. The reverse is more probable, as exercise at low temperature causes symptoms in asthmatic subjects. ${ }^{34}$ None of our skiers had childhood asthma. One of the referents satisfied our criteria for asthma, but none had self reported or physician diagnosed asthma. Based on the prevalence of asthma in Sweden, ${ }^{12}{ }^{13}$ we should have expected to find two cases of self reported asthma among the referents. That we did not was probably due to the small series. Our main purpose of including a referent group, however, was to compare bronchial responsiveness between skiers and non-skiers, not to establish a control group for estimating asthma prevalence in non-skiers. Bronchial responsiveness can be evaluated only if comparisons are made with an own reference group in which identical bronchial provocation tests have been performed. As a cut off level for bronchial hyperresponsiveness we chose the 10th centile of the concentration which yielded a $20 \%$ decrease in forced expiratory volume in one second in the referent group, as we regarded this as a strict and non-biased criterion (which left only three referents as hyperresponsive).

\section{ANTIASTHMATIC AGENTS}

Antiasthmatic drugs, especially $\beta_{2}$ agonists, are frequently used by cross country skiers. According to the medical committee of the International Ski Federation, $37 \%$ of the short distance competitors with a final position among the 15 best in the 1991 world championship used antiasthmatic drugs (unpublished data). In a postal inquiry $18 \%$ of cross country skiers and $7 \%$ of referents admitted using antiasthmatic drugs. ${ }^{2}$ Use of these drugs in the general population was recently reported as $6 \cdot 8 \% .{ }^{14} \beta_{2}$ Agonists have been claimed to increase physical performance. Several attempts to show an ergogenic effect of salbutamol have failed, ${ }^{15-17}$ and recently we failed to detect increased physical performance after terbutaline inhalation in non-asthmatic athletes exercising at low temperature (unpublished data).

$\beta_{2}$ Agonists reportedly have anabolic effects in animals. ${ }^{18-20}$ These effects, which have not been shown in humans, have been recorded after very high doses, and it is not plausible that an anabolic effect could be elicited by inhaling short acting $\beta_{2}$ angonists in humans even if high doses were used. Inhalation of salbutamol did, however, increase high intensity power output on

\section{Clinical implications}

- Half of the investigated cross country skiers had asthma symptoms and bronchial hyperresponsiveness or self reported asthma

- $80 \%$ Of the cross country skiers had asthma symptoms or bronchial hyperresponsiveness, or both

- The use of antiasthmatic drugs among cross country skiers is motivated by a high prevalence of asthma in these athletes

- In this series symptoms and bronchial hyperresponsiveness in the skiers were the same in the summer as in winter

- Strenuous exercise at low temperature is a probable cause of asthma

a bicycle ergometer, ${ }^{21}$ and oral salbutamol increased voluntary muscle strength in humans. ${ }^{22}$ We cannot deny categorically that these effects might be relevant in short term intense anaerobic work but we think that they would be lost in skiing and other types of prolonged work.

In this study 15 of 42 skiers (36\%) used antiasthmatic drugs regularly. Possible explanations for this high usage as compared with that in the study by Larsson $e t a l^{2}$ are twofold. Firstly, we included only élite skiers, who may have had a history of more intensive training than skiers selected on a general basis; secondly, the skiers studied by Larsson et al were younger (mean age 18) than those in our series.

Of the 10 skiers who did not have asthma according to our criteria (normal bronchial responsiveness) but who were taking antiasthmatic agents, all had symptoms of asthma. Nine had physician diagnosed asthma and all 10 were receiving inhaled steroids. Possibly these skiers had asthma but also normal bronchial responsiveness owing to regular long term treatment with inhaled steroids. ${ }^{23}$ On the other hand, if skiers believed that treatment with antiasthmatic drugs improved athletic performance they might overreport airways symptoms in order to excuse the drug. For the same reason there might be a risk of a falsely high prevalence of self reported and, possibly, physician diagnosed asthma in the group, although these questions seem to have high specificity in epidemiological studies. ${ }^{25}$

As measurements of bronchial responsiveness have low specificity for asthma, it may be that we overestimated the prevalence of the condition in our series. Weighing against any such small possibility, however, is the strength of our data, which speak in favour of a very high asthma prevalence among skiers. We found no evidence of overuse of antiasthmatic drugs among our cross country skiers; nine skiers who fulfilled our asthma criteria did not use antiasthmatic drugs regularly. Rather, our results indicate that many of the skiers needed antiasthmatic treatment.

Regular use of $\beta_{2}$ agonists may lead to increased bronchial responsiveness. ${ }^{23} 2426-28$ On this basis it is theoretically possible that any bronchial hyperresponsiveness found in our skiers may have been caused by regular $\beta_{2}$ agonist treatment. Most of the skiers who used $\beta_{2}$ agonists regularly, however, did not have bronchial hyperresponsiveness. Possibly this is explained by the concomitant use of inhaled steroids. Thus regular $\beta_{2}$ agonist treatment could not have influenced our results and led to an overestimation of asthma among the cross country skiers.

The prevalence of asthma in athletes has been studied only rarely and with conflicting results. In the 
1984 American Olympic team about $11 \%$ of athletes had asthma or exercise induced bronchoconstriction.' The figures agreed with those of Weiler et al, who found self reported asthma in $12 \%$ of football players; basketball players had a low asthma prevalence. ${ }^{29}$ In a study from Portugal Gomes et al found normal bronchial responsiveness in élite runners. ${ }^{30}$ In another study swimmers had a higher prevalence of asthma and bronchial hyperresponsiveness than other athletes and the authors postulated a relation with ambient swimming pool conditions. ${ }^{31}$

To our knowledge there are no other studies of skiers or other athletes performing exercise at low temperatures. From the few reports available there is no evidence that strenuous training by itself increases the risk of asthma. Strenuous training at low temperatures, however, seems to be pathogenetic for asthma, possibly due to the repeated breathing of large amounts of cold air.

The expert technical help of Britt-Marie Sundblad and Wang Zhi-Ping is acknowledged. We thank the department of clinical physiology, Hospital of Östersund, for spirometry. The study was partly financed by grants from the Swedish National Centre for Research in Sports.

1 Voy RO. The US Olympic committee experience with exercise-induced bronchospasm. Med Sci Sports Exerc 1984;18:328-30.

2 Larsson L, Hemmingsson P, Boethius G. Self-reported obstructive airwa symptoms are common in young cross-country skiers. Scandinavian fournal of Medicine and Science in Sports (in press).

3 Strauss RH, McFaddan ER, Ingram RH, Jaeger J. Enhancement of exerciseinduced asthma by cold air. N Engl f Med 1977;297:743-7.

4 Strauss RH, McFadden ER, Ingram RH, Deal EC, Jaeger J. Influence of heat and humidity on the airway obstruction induced by exercise in asthma. IClin Invest 1978;61:433-40.

5 Larsson K, Hendenström H, Malmberg P. Learning effect, variation during office hours and reproducibility of static and dynamic spirometry. office hours and reproduci
Respiration 1987;51: 214-22.

6 Hendenström H, Malmberg P, Fridriksson HV. Reference values for lung function tests in men: regression equations with smoking variables. Ups $\mathcal{F}$ Med Sci 1986;91:299-310.

7 Hedenström H, Malmberg P, Agarwal K. Reference values for lung function tests in females. Regression equations with smoking variables. Clinica Respiratory Physiology 1985;21:551-8.

8 Malmberg $\mathrm{P}$, Larsson $\mathrm{K}$, Thunberg $\mathrm{S}$. Increased lung deposition and biological effect of methacholine by use of a drying device for bronchial provocation tests. Eur Respir F 1991;4:890-8.

9 Amariv I, Plit M. Temperature and relative humidity response to inhaled histamine in normal subjects. Am Rev Respir Dis 1989;140:1416-20.

10 Dosman JA, Hodgson WC, Cockcroft DW. Effect of cold air on bronchial response to inhaled histamine in patients with asthma. Am Rev Respir Dis response to inhaled 1 144:45-50.

11 Litmanen H, Pekkarinen H, Randell J, Kononoff A, Tukiainen H. Airway response to inhaled histamine after exercising in the cold in healthy subjects. Eur Respir f 1992;5(suppl 15):445s.
12 Larsson L, Boethius G, Uddenfeldt M. Differences in utilization of asthma drugs between two neighbouring Swedish provinces: relation to symptom reporting. Eur Respir f 1993;6:198-203.

13 Lundbäck B, Nyström L, Rosenhall L, Stjernberg N. Obstructive lung disease in northern Sweden: respiratory symptoms assessed in a postal survey. Eur Respir f 1991;4:257-66.

14 Larsson L, Boethius G, Uddenfeldt $M$. Differences in utilization of asthma drugs between two neighbouring Swedish provinces-relation to prevalence of obstructive airway disease. Thorax (in press).

15 Morton AR, Papilia SM, Fitch KD. Is salbutamol ergogenic? the effects of salbutamol on physical performance in high-performance nonasthmatic athletes. Clinical foumal of Sport Medicine 1992;2:93-7.

16 McKenzie DC, Rhodes EC, Stirling DR, Wiley JP, Dunwoody DW, Filsinger IB, et al. Salbutamol and treadmill performance in non-atopic athletes. Med Sci Sports Exerc 1993;15:520-2.

17 Freeman W, Packe GE, Cayton RM. Effect of nebulised salbutamol on maximal exercise performance in men with mild asthma. Thorax 1989;44: 942-7.

18 Choo J, Horan MA, Little RA, Rothwell NJ. Anabolic effects of clenbuterol on skeletal muscle are mediated by $\beta 2$-adrenoceptor activation. Am $\mathcal{J}$ Physiol 1992;263:E50-6.

19 Beerman DH, Butler WR, Hogue DE, Fishell VK, Dalrymple RH, Ricks CA et al. Cimaterol-induced muscle hypertrophy and altered endocrine status in lambs. F Anim Sci 1987;65:1514-24.

20 Martinez JA, Portillo MP, Larralde J. Anabolic actions of a mixed $\beta$ adrenergic agonist on nitrogen retention and protein turnover. Horm Metab Res 1991;23:590-3.

21 Signorile JF, Kaplan TA, Applegate B, Perry AC. Effects of acute inhalation of the bronchodilator, albuterol, on power output. Med Sci Sports Exerc 1992;24:638-42.

22 Martineau L, Horan MA, Rothwell NJ, Little RA. Salbutamol, a $\beta 2$ adrenoceptor agonist, increases skeletal muscle strength in young men. Clin Sci 1992;83:615-21.

23 Kerrebijn KF, Essen-Zandvliet EEM van, Neijens HJ. Effect of long-term treatment with inhaled corticosteroids and beta-agonists on the bronchial responsiveness on children with asthma. I Allergy Clin Immunol 1987;79: respons.

24 Kraan J, Koeter GH, Mark WVD, Sluiter HJ, Vries KD. Changes in bronchial hyperreactivity induced by 4 weeks of treatment with antiasthmatic drugs in patients with allergic asthma: a comparison between budesonide and terbutaline. $\mathcal{F}$ Allergy Clin Immunol 1985;76:628-36.

25 Torén $\mathrm{K}$, Brisman J, Järvholm B. The assessment of asthma and asthma-like symptoms in adults using questionnaires-a literature review. Chest (in press).

26 Larsson K, Martinsson A, Hiemdahl P. Influence of $\beta$-adrenoceptor function during terbutaline treatment on allergen sensitivity and bronchodilato response to terbutaline in asthmatic subjects. Chest 1992;101:953-60.

27 van Schayck CP, Graafsma SJ, Visch MB, Dompeling E, van Weel C, van Herwarden LA. Increased bronchial hyperresponsiveness after inhaling Herwaarden $L A$. salbutamol during 1 year is not caused

28 Vathenen AS, Knox AJ, Higgins BG, Britton IR, Tattersfield AE. Rebound increase in bronchial responsiveness after treatment with inhaled Rebound increase in bronchial resp
terbutaline. Lancet 1988;i:554-8.

29 Weiler JM, Metzger WJ, Donnelly AL, Crowley ET, Sharath MD. Prevalence of bronchial hyperresponsiveness in highly trained athletes. Chest 1986;90 23-8.

30 Gomes I, Figueiredo MM, Oliveira J, Almeida J, Coelho M, Marques A Bronchial responsiveness to inhaled methacholine in well trained runners. Eur Respir 7 1992;5(suppl 15):455s.

31 Drobnic F, Banquells M, Casan P, Miralda R, Sanchi J, Freixa A, et al. Bronchial hyperresponsiveness in elite sportsmen. Eur Respir f 1992, 5(suppl 15):456s.

(Accepted 10 September 1993)

\section{Importance of placement of intra-articular steroid injections}

\section{A Jones, M Regan, J Ledingham, M Pattrick, A Manhire, M Doherty}

Rheumatology Unit, City Hospital, Nottingham NG5 1PB

A Jones, research fellow M Regan, senior registrar $\mathrm{J}$ Ledingham, research fellow A Manhire, consultant radiologist

M Doherty, senior lecturer

Manchester General Hospital, Manchester M8 7PJ

M Pattrick, consultant physician

Correspondence to: Dr Jones.

$B M \mp 1993 ; 307: 1329-30$
Intra-articular corticosteroid injections are widely used in clinical practice, but their effect is variable and their value remains doubtful. ${ }^{1}$ One possible explanation for this variability might be inaccurate injection. We conducted this study to determine the accuracy of joint injections, factors associated with inaccuracy, and the effect of placement on clinical response.

\section{Patients, methods, and results}

The study was approved by the local hospital ethics committee. Patients in whom intra-articular steroid injections were indicated were asked if they wished to participate. After patients had given informed consent, synovitis in the index joint ${ }^{23}$ and at other sites was assessed. ${ }^{4}$ Local synovitis was graded according to an articular index developed for use at the knee. An "active," inflamed knee is defined by the presence of three or more of the following: stiffness lasting for more than 30 minutes in the early morning or after inactivity, synovial thickening, local warmth, tenderness, and moderate synovial effusion. ${ }^{23}$ Depot methylprednisolone was used for all injections and was mixed with a radiographic contrast medium, iopamidol. The index joint was aspirated and injected, and the patient had a single plain radiograph of this joint. Patients were reviewed at six weeks by the same assessor; the Ritchie index and the assessment of synovitis were repeated blind to the results of the previous radiological clinical findings. ${ }^{2-4}$ Radiographs were read blind by one consultant radiologist (AM). Results were analysed by a $\chi^{2}$ test.

Overall, 109 patients were studied; their median age was 68 (range 23-89). Forty four patients had rheumatoid arthritis, 52 osteoarthritis, and 13 other disease. The joints injected and the accuracy of placement at each joint site are shown in the table. One patient failed to attend for radiography and thus 108 radiographs were evaluable. Fifty six injections were intra-articular and 31 extra-articular; in 21 the location was uncertain because of a lack of contrast in the radiograph. 